\title{
External heat transfer enhancement of a beta- type Stirling engine with fins as regenerator
}

\author{
Thavamalar Kumaravelu ${ }^{1}$,Syamimi Saadon ${ }^{1}$ \\ ${ }^{1}$ Aerodynamics, Heat Transfer and Thermofluids Group, Department of Aerospace Engineering, \\ Faculty of Engineering, University Putra Malaysia, 43400 Serdang, Selangor
}

\begin{abstract}
The Stirling engine is an externally heat engine closed loop with a high theoretical performance and low emissions compared to other conventional engines. This property nowadays becomes very advantageous due to its multi-fuel capacity including solar, biogas and geothermal energy. In this study, a numerical investigation of the effect of a circular, pin, and rectangular fins on the performance of the Stirling engine is introduced. The 3D CFD model was performed and validated with previous experimental study. The power output, heat transfer rate and efficiency were studied for all cases of fins. The results indicated a close agreement between the numerical and the experimental results with average difference for power of the engine approximately around $2.8 \%$. The efficiency decrease with the increase of the rotational speed of the engine and the highest efficiency is indicated for rectangular fins.
\end{abstract}

\section{Introduction}

Latest trend in the world gives extra attention regarding the best ways of utilizing the sources of energy around the living environment, and by doing it also reducing the environmental pollution. This create the awareness among the researchers and has encouraged them to do research and development efforts in the fields of alternative energy sources. Cost effective use of the exhaustible sources of energy, and the re-use of the usually wasted forms of energy are the other issues that also create the interest among the researchers about the substitutional energy (M. J. Dadi et al., 2012).

Waste heat is the heat generated in a system by means of combustion of fuel or chemical reactions and then dumped into the atmosphere even if it could still be recycled for some useful and economic purpose. The vital value of heat is not the quantity but rather of its quality. The approach on how to recuperate this heat solely depends on the temperature of the waste heat gases and the cost involved (M. J. Dadi et al., 2012). These increments of the heat sources generated in our living environment will ultimately rise the ambient temperature and may lead to global warming if it is not handled accordingly. For that reason, waste heat should be garnered and recycled as electric power (H.J. Shih, 2019).

The current technology seizures and alters this mostly unused waste heat to produce emission-free electricity, permitting the industrial manufacturer to place their wasted energy back into the process that created it. There has been a lot of researches and developments of 
these systems that are proficient of creating electricity even from waste heat at low temperatures (H. Jouhara et al., 2018).

The temperature of the waste heat plays a significant part on the approach taken to recuperate these waste heat. These waste heat can be improved by numerous forms of heat recovery systems such as the Stirling engines, Thermo-Electric (TE), Organic Rankine Cycles (ORC) and Micro Rankine Cycles (MRC). Stirling engines are external combustion engine that does a thermodynamic cycle using working fluid such air, helium or hydrogen. The ideal thermal efficiency of the engine achieves the Carnot efficiency, even though real efficiency values gained are typically lesser than $30 \%$ due to the struggle of the engine construction and the unalterable measures that occurs while the system is in operation.

Stirling engine offer a promising deal for exploiting the enormous quantity of waste heat discharged from industrial processes and renewable thermal energy sources to produce electrical power (A.K. Almajri et al., 2017). This engine is also expected to produce low pollution, noiseless power-generating machines with tremendous fuel economy and multifuel ability. As a result, Stirling engine has received much consideration from researchers in energy associated fields in contemporary years (H.S. Yang et al., 2017).

Stirling engines, as external combustion engines, have outstanding typical features and great dependability, allowing them to be considered as a waste heat recovery system by converting exhaust heat to power. The outside edge of the tubes is where the heat transfer mechanism in the Stirling engine's heater encounters the greatest heat resistance. Adding heat transfer enhancement materials to the area between the exterior of the tubes and determining the optimal strategy for combining heat transfer enhancement materials is one way to reduce heat transfer resistance and boost heat transfer between the exhaust waste gas and working medium. Various researchers have conducted extensive study to improve the heat transfer characteristics of tube heat exchangers. However, the regions linked to outer tube geometries with various fin attachments have yet to be investigated, and this portion is critical for an external combustion engine to improve heat transmission.

\section{Methodology}

Computational fluid dynamics modelling is used to validate the model of $\beta$-type Stirling engine. Modelling of the Stirling engine is done using SOLIDWORKS which is then imported into ANSYS workbench for CFD analysis.

The purpose of this research is to aid in the preliminary analysis of a Stirling engine for waste heat recovery, with an emphasis on heat transmission. By examining the influence of fins attachment, which is rectangular, circular, and pin, the beginning point uses the computational technique to find characteristics that affect the heat transfer rate. The numerical model of the Stirling engine's new tubular heater will then be integrated into the waste heat recovery system.

The first part of the simulation is to validate the Stirling engine model with a previous research paper (R. Ben-Mansour et al., 2017). The engine's model with rhombic drive mechanism is shown below in Fig. 1 consisting of a displacer and a piston located in a cylinder. Different equations will be utilized to model and analyze the thermal performance of the Stirling engine in order to obtain the heat transfer rate, efficiency and power output. 


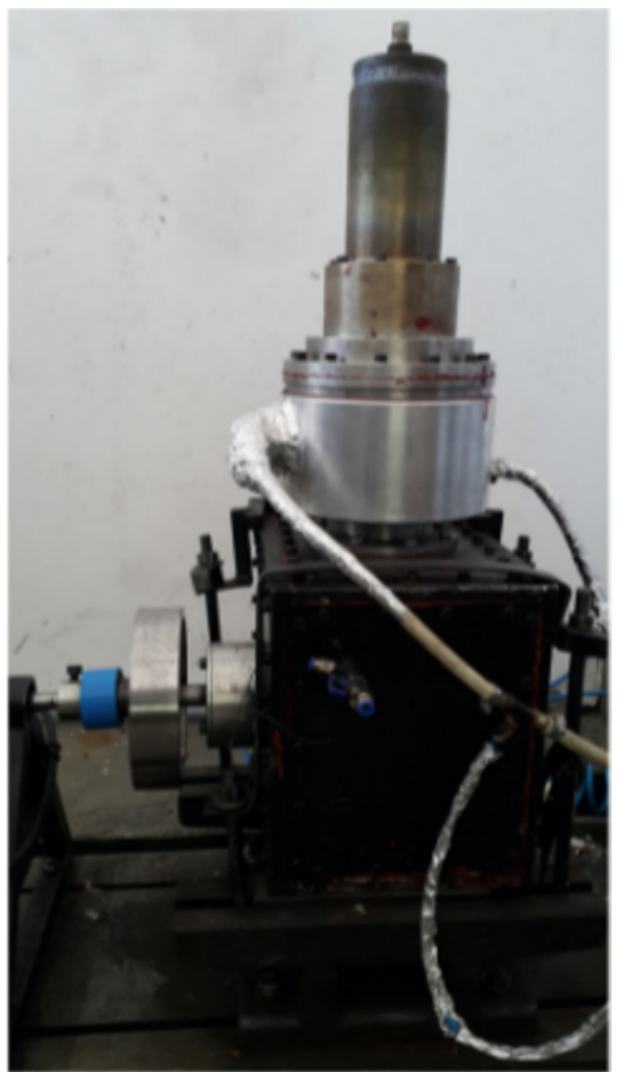

Fig. 1. Prototype of the Stirling engine (F. Aksoy et al., 2017).

The engine contains a small gap that connects the expansion and compression zones (see Fig. 2). Normally, this narrow channel gap, which could be seen in Fig. 3, is filled with regenerator materials; however, there is no regenerator here. Because the issue might be addressed as axis-symmetric geometry, just half of the domain is simulated. The dimensions of the simulated geometry are described here in Table 1. 


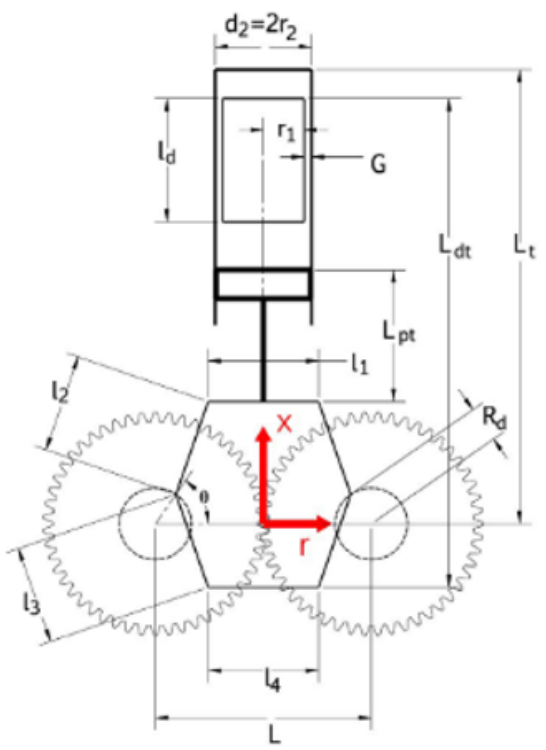

Fig. 2. Schematic view of beta-type, rhombic-driven Stirling engine (R. Ben-Mansour et al., 2017).

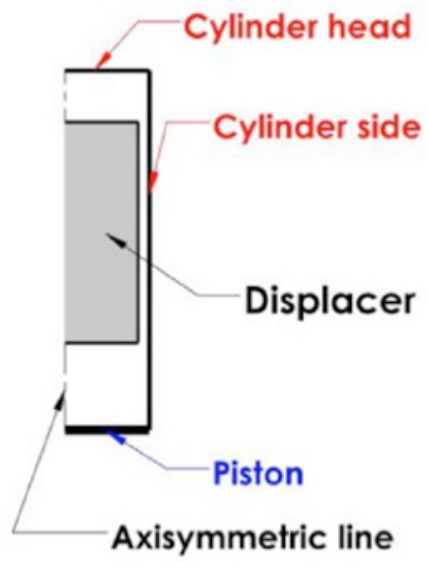

(a)

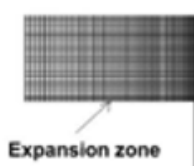

Narrow channel

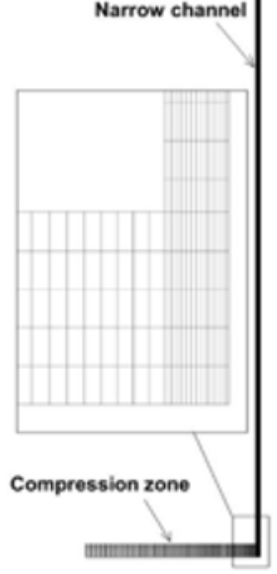

(b)

Fig. 3. Computational domain of beta-type Stirling engine (R. Ben-Mansour et al., 2017). 
Table 1. Design parameter for geometric modelling of the Beta-type Stirling engine (R. Ben-Mansour et al., 2017)..

\begin{tabular}{|c|c|}
\hline Parameters & Specifications \\
\hline Engine type & Beta \\
\hline Driving mechanism & Rhombic \\
\hline $\mathrm{r}_{1}(\mathrm{~mm})$ & 20 \\
\hline $\mathrm{r}_{2}(\mathrm{~mm})$ & 20.5 \\
\hline $\mathrm{L}_{\mathrm{d}}(\mathrm{mm})$ & 79.46 \\
\hline $\mathrm{l}_{1}=\mathrm{l}_{2}=\mathrm{l}_{3}=\mathrm{l}_{4}(\mathrm{~mm})$ & 18 \\
\hline $\mathrm{G}(\mathrm{mm})$ & 0.5 \\
\hline $\mathrm{L}_{\mathrm{t}}$ & 158 \\
\hline $\mathrm{L}_{\mathrm{pt}}$ & 50.93 \\
\hline $\mathrm{L}_{\mathrm{dt}}$ & 163.74 \\
\hline $\mathrm{R}_{\mathrm{d}}(\mathrm{mm})$ & 3.5 \\
\hline
\end{tabular}

The fins configurations were illustrated in Fig. 4 where circular, pin and rectangular fins enhance the heat transfer of the heating and cooling sections of the Stirling engine. Steel is used as the material of the fins since it is more cost-effective though it has less thermal conductivity than copper.

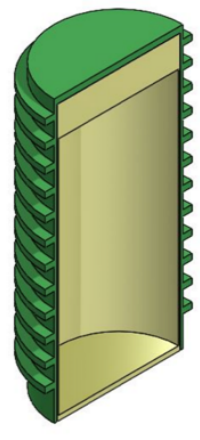

(a)

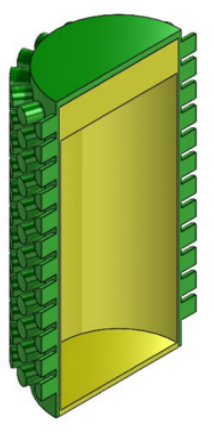

(b)

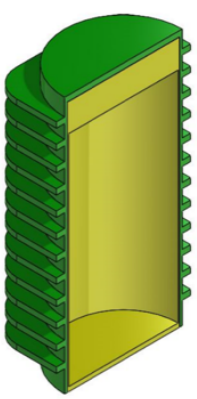

(c)

Fig. 4. Fins configurations (a) circular fin, (b) pin fin, (c) rectangular fin

For the region adjacent to the wall of fluid and fins, mesh changes were used. Grid dependency is tested for three separate grids to verify the grid's solution independence: 3.1 million, 3.9 million and 4.2 million cells respectively. The error is less than $2.61 \%$ for the engine power and less than $4.21 \%$ for the temperature between the finest grid with 4.2 million cells and the grid with 3.9 million cells. The grid settings of 4.2 million cells are therefore used in the present study for further investigations.

The total inlet heat transfer of hot fluid, $Q_{\text {in }}$ can be expressed as:

$$
\mathrm{Q}_{\text {in }}=\mathrm{M}_{\mathrm{h}} \mathrm{C}_{\text {p.h }}\left(\mathrm{T}_{\text {in, }, \mathrm{h}}-\mathrm{T}_{\text {out }, \mathrm{h}}\right)
$$


where, $\mathrm{M}_{\mathrm{h}}$ is the mass flow rate of heating fluid, $\mathrm{C}_{\mathrm{p} . \mathrm{h}}$ is the specific heat of heating fluid and $\mathrm{T}_{\mathrm{in}, \mathrm{h}}$ and $\mathrm{T}_{\text {out,h }}$ are the inlet and outlet of heating fluid temperature, respectively. The total outlet heat transfer $Q_{\text {out }}$ can be calculated by:

$$
\mathrm{Q}_{\text {out }}=\mathrm{M}_{\mathrm{c}} \mathrm{C}_{\mathrm{p} . \mathrm{c}}\left(\mathrm{T}_{\mathrm{in}, \mathrm{c}}-\mathrm{T}_{\text {out }, \mathrm{c}}\right)
$$

where, $\mathrm{M}_{\mathrm{c}}$ is the mass flow rate of cooling fluid, $\mathrm{C}_{\mathrm{p.c}}$ is the specific heat of cooling fluid and $\mathrm{T}_{\mathrm{in,c}}$ and $\mathrm{T}_{\mathrm{out}, \mathrm{c}}$ are the inlet and outlet of cooling fluid, respectively.

The net heat transfer $Q_{n e t}$ can be calculated by

$$
\mathrm{Q}_{\text {net }}=\mathrm{Q}_{\text {in }}-\mathrm{Q}_{\mathrm{out}}
$$

While the power output $W_{\text {out }}$ is considered and calculated numerically from:

$$
W_{\text {out }}=\frac{\omega}{2 \pi} \sum_{i=1}^{N} 0.5\left(p_{i-1}+p_{i}\right) \cdot\left(V_{i \cdot}-V_{i-1}\right)
$$

Efficiency of the engine can be calculated from:

$$
\eta=\frac{Q_{n e t}}{Q_{\text {in }}}
$$

\section{Results and discussion}

The model is validated by comparing the simulation results with previous study conducted by other researchers (R. Ben-Mansour et al., 2017). The working fluid used in this model is air with charged pressure 1 bar and the speed of the engine is set at $408 \mathrm{rpm}$. The cylinder walls of the Stirling engine has a thickness of $1 \mathrm{~mm}$ and possess thermal conductivity of 43 $\mathrm{W} / \mathrm{m} . \mathrm{K}$, density of $7840 \mathrm{~kg} / \mathrm{m}^{3}$ and specific heat of $450 \mathrm{~J} / \mathrm{kg} . \mathrm{K}$. The expansion zone temperature is set at $773 \mathrm{~K}$ while the compression zone temperature is at $300 \mathrm{~K}$. The thermal boundary conditions at these two zones are limited to $800 \mathrm{~K}$ and $300 \mathrm{~K}$, respectively. Meanwhile, the exterior cylinder side walls are disclosed to a temperature that varies according to the $\mathrm{x}$-axis:

$$
T(x)=\left\{\begin{array}{c}
T_{C}(K), \text { if } x \leq 0.08 m \\
T_{C}+\frac{x-0.08}{0.158-0.08}\left(T_{H}-T_{C}\right)(K)
\end{array}, \text { if } x>0.08 m\right\}
$$

where $\mathrm{T}_{\mathrm{C}}$ and $\mathrm{T}_{\mathrm{H}}$ is the cold and hot temperature, respectively.

Fig. 5 shows the relation of power output in this study and the previous study. The behaviors of both cases are approximately consistent. The average difference for power of the engine is approximately $2.8 \%$ while the maximum and minimum differences are $6.24 \%$ and $0.5 \%$ respectively. These could be due to the assumptions made in the modeling and simulation process. 


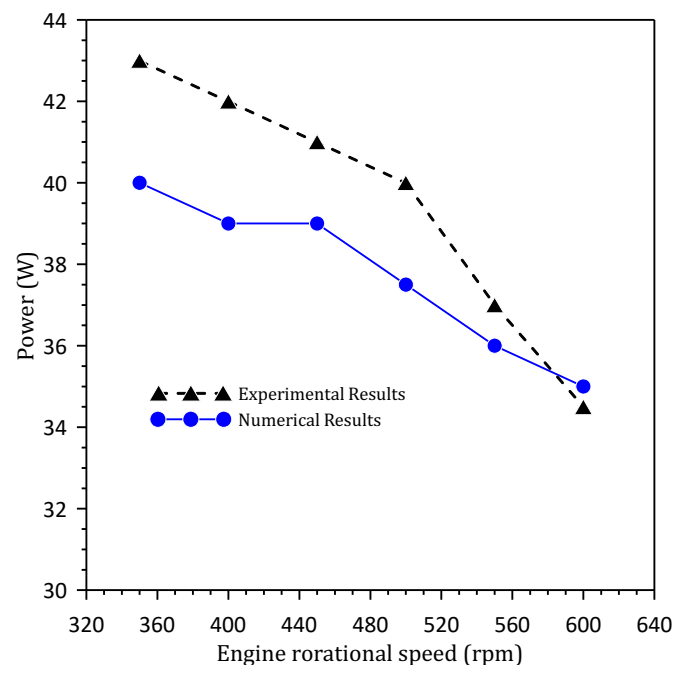

Fig. 5. Validation of numerical results by comparing with previous experimental results.

Fig. 6 shows the heat transfer rate profiles obtained by the Stirling engine model for without fins (R. Ben-Mansour et al., 2017), circular fins, pin fins, rectangular fins. It demonstrates the declination in heat transfer as the rotational engine speed increases. That can be explained as the rectangular fins increase the surface area where the turbulence increases in the heating fluid side. It should be remembered that the mechanisms for losses depend primarily on the dysfunctional actions of both thermodynamics, fluid dynamics, and ultimately, Phenomena of heat transfer inside the engine. Hence the heat loss-related differences are discussed in the following subsections along with the process of measuring each loss. Consequently, only fluid layers near the heating walls would have high temperature compared to other region in the expansion chamber due to diffusion heat transfer mainly.

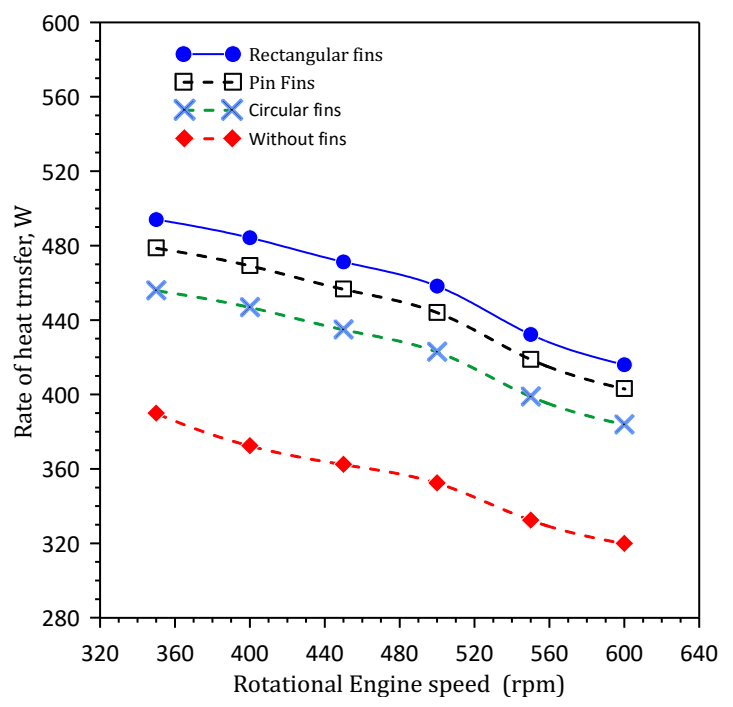

Fig. 6. The heat transfer rate of the engine versus the rotational engine speed.

The efficiency of the engine is showed in Fig. 7 where the efficiency decrease with the increase of the rotational speed of the engine and the highest efficiency is indicated is the rectangular fins following the numbers between $13 \%$ and 19\%. Pin fins have high efficacy 
than the circular fins and without fins case. It can be concluded that the efficiency is enhanced by utilizing any type of fins.

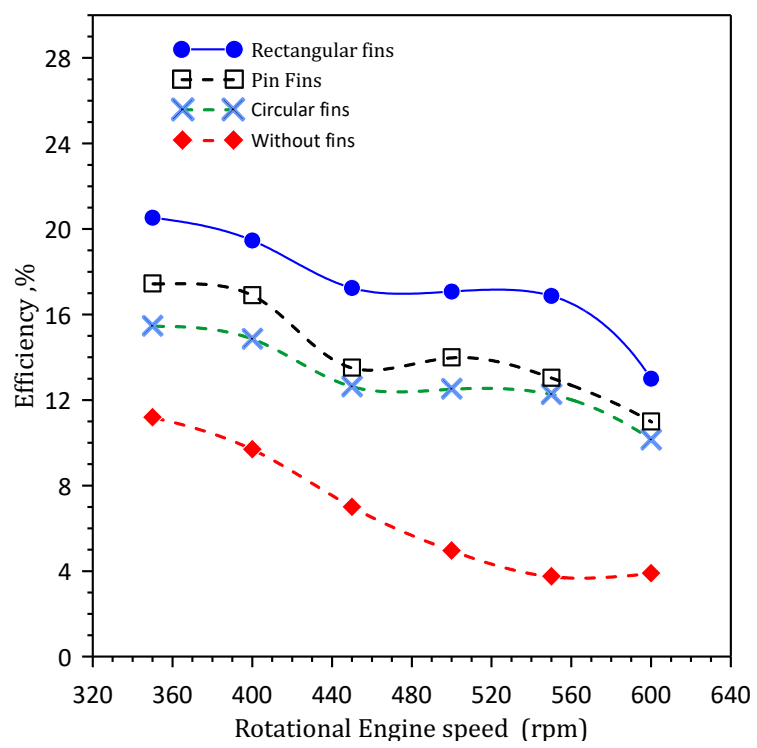

Fig. 7. The efficiency of the engine versus the rotational engine speed.

The results show that rectangular fins received the highest heat transfer rate compared to other fins geometry due to the increase surface area. Besides that, rectangular fins produce the highest heat transfer performances due to the increase in turbulence flow at the heating fluid side.

Fig. 8 compares the power output calculated by the models with fins attachment and without fins of CFD at different rotation speed. The Stirling engine power is illustrated in Fig. 8 where the power decreased with the increase of the rotational speed. Maximum power output for all the Stirling engine model were obtained at $350 \mathrm{rpm}$. The maximum power obtained were $101.74 \mathrm{~W}, 82.57 \mathrm{~W}, 72.32 \mathrm{~W}$, and $40.08 \mathrm{~W}$ respectively, for without fins, circular fins, pin fins, rectangular fins Stirling engine model.



Fig. 8. The power of engine versus the rotational engine speed. 


\section{Conclusion}

A three-dimensional Computational Fluid Dynamics (CFD) simulation is performed with three types of fins; circular fins, pin fins and rectangular fins. The numerical model was validated with previous study and the differences were acceptable with an average difference of about $2.8 \%$. The results show that rectangular fins produce the highest heat transfer rate thanks to its higher surface area compared to the other fins and also the increase in turbulence flow at the heating fluid side.

\section{Acknowledgement}

This research was funded by a grant from Ministry of Higher Education of Malaysia (FRGS Grant: FRGS/1/2018/TK07/UPM/02/2).

\section{References}

1. M.J. Dadi, I. M. Molvi, A. V. Mehta, Int. J. Adv. Eng.Tech. 3 (1), 189-195 (2012)

2. H.J. Shih, Energies 12 (7), 1322 (2019)

3. H. Jouhara, N. Khordehgah, S. Almahmoud, B. Delpech, A. Chauhan, S. A. Tassou, Therm. Sc. Eng. Prog. 6, 268-289 (2018)

4. A.K. Almajri, S. Mahmoud, R. Al-dadah, Energy Conv. Management 145, 93-106 (2017)

5. H.S. Yang, C. H. Cheng, Appl. Energy 200, 62-72 (2017)

6. R. Ben-Mansour, A. Abuelyamen, E. M. A. Mokheimer, Energy Conv. Management 152, 354-365 (2017) 